\title{
Alternative specimen extraction techniques after laparoscopic emergency colectomy in inflammatory bowel disease
}

\author{
Tjibbe J. Gardenbroek • Emma J. Eshuis • \\ Gijs J. D. van Acker · Pieter J. Tanis • \\ Willem A. Bemelman
}

Received: 14 January 2011/ Accepted: 13 August 2011/Published online: 10 September 2011

(C) The Author(s) 2011. This article is published with open access at Springerlink.com

\begin{abstract}
Background Omitting the extraction site incision potentially further decreases the abdominal wall trauma in laparoscopic surgery. The purpose of this study was to report the results of alternative specimen extraction techniques after laparoscopic emergency colectomy in patients with inflammatory bowel disease (IBD).

Methods Ten consecutive patients with IBD underwent (sub)acute emergency colectomy for refractory disease from October 2009 until December 2010. The specimen was retrieved via the stoma site in three and transrectally in seven patients. Patient data were prospectively collected. In case of later completion proctectomy and pouch procedure, adhesions were systematically scored.

Results The extraction techniques were all feasible. Median operative time was 219 (interquartile range (IQR), 197-232) min. The pain scores and morphine requirement in patients decreased quickly after surgery. No infectious complications occurred. In five patients, a completion proctectomy was performed at a median time of 7 (IQR, 3.8-9.3) months after colectomy. All patients showed absence of any adhesions in the pelvis. In two patients,
\end{abstract}

T. J. Gardenbroek - E. J. Eshuis · P. J. Tanis ·

W. A. Bemelman ( $\square)$

Department of Surgery, Academic Medical Center,

G4-146.1, PO Box 22660, 1100 DD Amsterdam,

The Netherlands

e-mail: w.a.bemelman@amc.uva.nl

T. J. Gardenbroek · E. J. Eshuis

Department of Gastroenterology and Hepatology,

Academic Medical Center, Amsterdam, The Netherlands

G. J. D. van Acker

Department of Surgery, Medical Center Haaglanden,

The Hague, The Netherlands limited adhesions of the cut side of the mesentery were present.

Conclusions Specimen extraction via the rectum or stoma site is a safe, alternative way to extract the specimen after laparoscopic colectomy. No infectious complications were observed postoperatively and no pelvic adhesions were found during completion proctectomy.

Keywords Colitis - Inflammatory bowel disease . Colectomy $\cdot$ Laparoscopy $\cdot$ Extraction

Crohn's disease and (ulcerative) colitis are inflammatory bowel diseases (IBDs) that can affect the entire colon. Up to $75 \%$ of patients with Crohn's disease and approximately $10-30 \%$ of patients with ulcerative colitis will undergo surgery within the first decade after diagnosis [1-5].

Minimally invasive surgery (MIS) has been used in practically all colorectal procedures for both benign and malignant colorectal diseases [6-9]. Laparoscopic procedures have the advantages of a shorter postoperative stay, early return of bowel function, and decreased complications [8-12]. Still, in laparoscopic colorectal surgery, an abdominal incision is needed to remove the colonic specimen from the peritoneal cavity. This has led to the development of different techniques, such as single-incision laparoscopic surgery (SILS), natural orifice specimen extraction (NOSE), and natural orifice transluminal endoscopic surgery (NOTES). These techniques are designed to reduce abdominal wall trauma, thereby decreasing postoperative pain, improving cosmesis, and shortening of the recovery period [13-18].

This study was designed to report the feasibility and safety of two specimen extraction techniques without the need for an additional incision after laparoscopic 
(emergency) subtotal colectomy in patients with IBD refractory to medication and to report the intra-abdominal adhesions during completion proctectomy.

\section{Materials and methods}

All consecutive patients who underwent an acute or subacute laparoscopic subtotal colectomy for IBD colitis with a transrectal or stoma site specimen extraction technique from October 2009 until September 2010 were included. All patients consented before surgery. The insertion of additional ports and/or conversion to laparoscopy-assisted colectomy or laparotomy for reasons of patient safety was assured. Preoperative workup and patient preparation conformed to regular laparoscopic(-assisted) colectomy procedures, and bowel preparation was done in patients who had semi-acute surgery. An experienced laparoscopic surgeon performed all procedures. Patient data were prospectively collected and analyzed retrospectively.

\section{Surgical procedures}

\section{Laparoscopic subtotal colectomy with transrectal specimen extraction}

Surgery was performed under general anaesthesia, and patients received intravenous antibiotic prophylaxis. Patients were placed in the French position, with the legs abducted. A four-trocar approach (subumbilical, $10 \mathrm{~mm}$; right paramedian, 10 or $11 \mathrm{~mm}$; suprapubic, $10 \mathrm{~mm}$; left iliac fossa, $5 \mathrm{~mm}$ ) and a $30^{\circ}$ videoscope were used. A submesenterial window was created on the left side with identification and saving of the superior rectal artery and ureter. From there, distal to proximal close pericolic

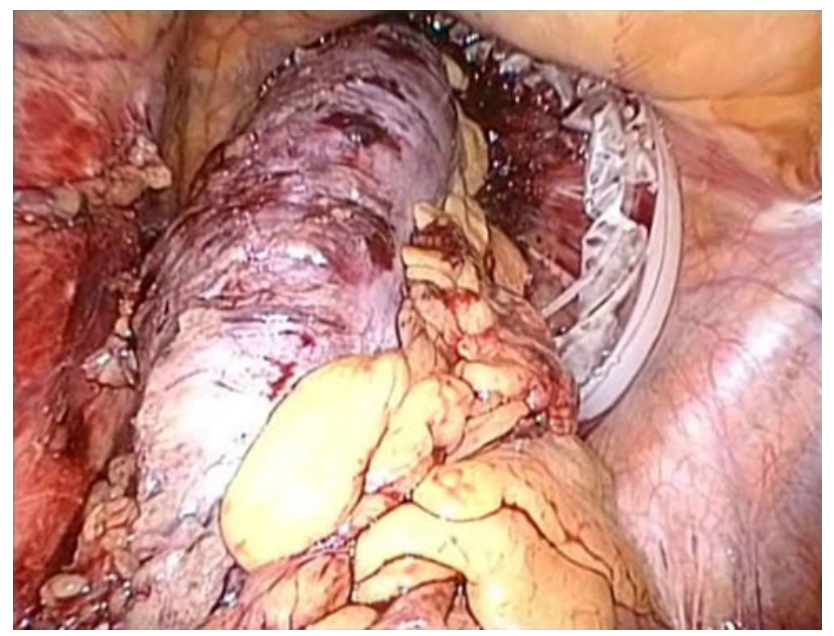

Fig. 1 Transrectal extraction of the colectomy specimen through the transrectally inserted wound protector dissection of the mesocolic and omental attachments of the colon with identification and transsection of the colic vessels was completed using ultrasonic dissection. The terminal ileum was transsected using a linear endoscopic stapler $\left(\right.$ Echelon $^{\mathrm{TM}} 60$ ENDOPATH $^{\circledR}$ stapler; Ethicon Endo-Surgery, Cincinnati, $\mathrm{OH})$. At the level of the promontorium, the proximal rectum was transsected by using the linear endoscopic stapler.

The rectum was irrigated with Betadine to ensure complete removal of residual stool before opening the stapling line of the rectal stump. To facilitate transrectal specimen extraction, a wound protector $\left(3 \mathrm{M}^{\mathrm{TM}}\right.$, St. Paul, MN) was inserted through the opened rectum and the colectomy specimen was then extracted in total (Fig. 1). After complete extraction of the colon, the rectal stump was closed by using another cartridge of the linear stapler. An end ileostomy was created at the right paramedian trocar site. The rectal stump was routinely drained for 5 days using a transanal catheter.

\section{Stoma site extraction}

The specimen can be extracted through the stoma site in two different types of procedures. For patients who require an end ileostomy, the procedure was conducted using the Single-Site Laparoscopy Access System (SILS, Ethicon Endo-Surgery, Inc.). The port was positioned at the location of the future ileostomy site. The laparoscopic colectomy was conducted as described above. The extraction of the colectomy specimen through the single port allowed proximal transsection of the terminal ileum to be performed extracorporeally with a linear stapler (Echelon ${ }^{\mathrm{TM}} 60$ ENDOPATH $^{\circledR}$ stapler). After correctly orientating the terminal ileum, an end ileostomy was created (Fig. 2).

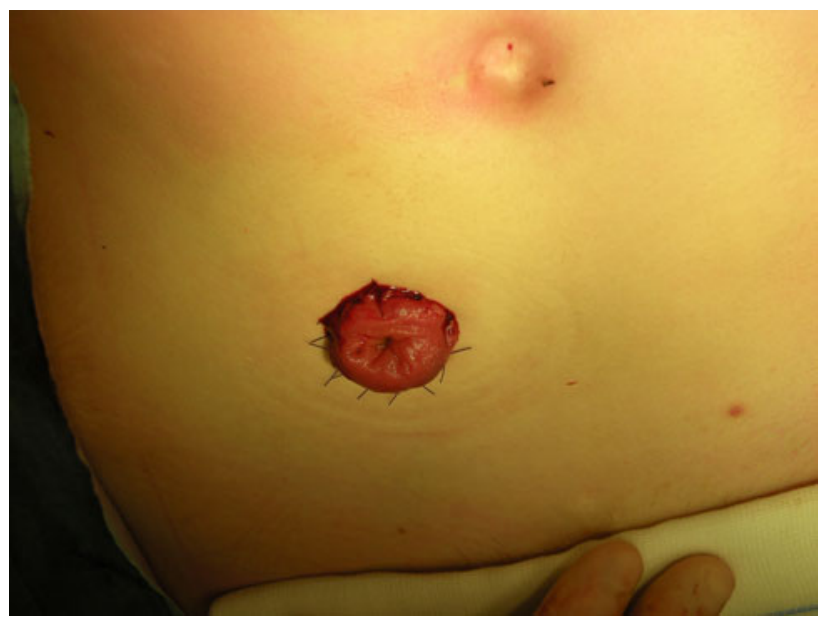

Fig. 2 Cosmetic result after single-port colectomy with an end ileostomy 
For patients with a previously constructed end ileostomy, the ileostomy was closed by using a linear stapler $\left(\right.$ Echelon $^{\mathrm{TM}} 60$ ENDOPATH $^{\circledR}$ stapler) and was repositioned intra-abdominally. A balloon trocar was inserted in the ileostomy site and three additional trocars (subumbilical, suprapubic, and left iliac fossa) were placed to perform the laparoscopic colectomy. After removal of the balloon trocar, a wound protector was placed at the ileostomy site, and the colonic specimen was extracted through the wound protector. The balloon trocar was then reinserted, and a side-to-end ileorectal anastomosis was performed laparoscopically using a double-stapling technique.

Outcome measures

The outcome measures were: feasibility of the specimen extraction techniques, operating time, reoperation rate (within 4 weeks after the operation), postoperative pain scores, morphine requirement, length of hospital stay, and postoperative complications (within 4 weeks after the operation). Postoperative pain was assessed by means of a visual analogue scale (VAS), where 0 represented no pain and 10 the worst pain imaginable. This VAS was measured at days 1-3 after operation. Complications were defined as any deviation from a normal postoperative recovery and were graded according to the Clavien scale [19].

Furthermore, adhesions were systematically scored in patients who underwent a completion proctectomy and pouch procedure. They were graded as no adhesions, limited adhesions, or numerous adhesions present, and their locations were described (e.g., pelvic, cut side of the mesentery).

Statistical analysis

SPSS version 18.0 for Windows ${ }^{\circledR}$ (SPSS Inc., Chicago, IL) was used for statistical analysis. Results for continuous data were expressed as median (interquartile range; IQR).

Table 1 Patient characteristics

\begin{tabular}{ll}
\hline & $(n=10)$ \\
\hline M:F ratio & $2: 3$ \\
Age (years) $^{\mathrm{a}}$ & $21.5(17.8-37)$ \\
BMI $^{\mathrm{a}}$ & $21.5(18.4-23.1)$ \\
Diagnosis & \\
Ulcerative colitis & 4 \\
IBD-U (undefined) & 3 \\
Crohn's disease & 3 \\
Preoperative medication & \\
Steroids & 2 \\
Biologicals & 6 \\
Disease duration (years) & \\
\hline
\end{tabular}

${ }^{a}$ Median (interquartile range)

\section{Results}

Between October 2009 and December 2010, ten consecutive patients who underwent laparoscopic subtotal colectomy were included. Seven patients underwent transanal specimen extraction, and three patients underwent extraction of the colectomy specimen via the stoma site, of which two patients had the SILS technique. The study included four men and sex women with a median age of 21.5 (IQR, 17.8-37) years. The median body mass index (BMI) was $21.5 \mathrm{~kg} / \mathrm{m}^{2}$ (IQR, 18.4-23.1; Table 1).

\section{Clinical outcomes}

Outcomes are summarized in Table 2. Previous abdominal surgery was performed in three patients; in two patients this was a laparoscopically created ileostomy, and in one patient a laparoscopic cholecystectomy.

Nine patients were operated in a subacute setting; one patient was operated in an acute setting. All patients had a medical refractory inflammatory bowel disease; two patients were preoperatively treated with high-dose

Table 2 Clinical outcomes

\begin{tabular}{|c|c|}
\hline & $(n=10)$ \\
\hline Operating time $(\min )^{\mathrm{a}}$ & $\begin{array}{l}219 \\
(197-232)\end{array}$ \\
\hline Length of resected bowel $(\mathrm{cm})^{\mathrm{a}}$ & $\begin{array}{l}93 \\
(75.8-116.5)\end{array}$ \\
\hline Postoperative hospital stay ${ }^{\mathrm{a}}$ & $7.5(4-10.5)$ \\
\hline \multicolumn{2}{|l|}{ Pain scores ${ }^{\mathrm{ab}}$ : } \\
\hline Postoperative day 1 & $4.5(2-6.3)$ \\
\hline Postoperative day 2 & $4.5(1.8-5.3)$ \\
\hline Postoperative day 3 & $3(1-4)$ \\
\hline Number of patients with $\mathrm{PCA}^{\mathrm{a}}$ & 9 \\
\hline Morphine requirement day 1 (mg) & $60(30-95)$ \\
\hline Morphine requirement day $2(\mathrm{mg})$ & $49(0-50)$ \\
\hline Morphine requirement day 3 (mg) & $0(0-0)$ \\
\hline $\begin{array}{l}\text { Complications grade } 1 \text { or } 2^{\mathrm{c}} \\
\text { (Ileostomy dysfunction) }\end{array}$ & 2 \\
\hline Complications $\geq$ grade $3^{\text {c }}$ & 0 \\
\hline Readmission within 30 days & 0 \\
\hline $\begin{array}{l}\text { Completion proctectomy and pouch procedure } \\
\text { performed }\end{array}$ & 5 \\
\hline $\begin{array}{l}\text { Time between colectomy and completion } \\
\text { proctectomy }(\mathrm{mo})^{\mathrm{a}}\end{array}$ & $7(3.8-9.3)$ \\
\hline Pelvic adhesions present & 0 \\
\hline \multicolumn{2}{|l|}{ a Median (interquartile range) } \\
\hline \multicolumn{2}{|c|}{$\begin{array}{l}\text { b Derived from nursing records, on a scale from } 1 \text { (no pain) to } 10 \\
\text { (worst pain) }\end{array}$} \\
\hline
\end{tabular}


steroids, and six patients with biologicals. One patient developed toxic colitis.

All colectomy specimen extraction techniques were feasible in the selected patients. One patient had a stoolloaded colon that restricted transrectal specimen extraction; in this case, the liquid stool and air was drained via an incision of the externalised large bowel. Thereafter, the specimen could be extracted completely.

After surgery, two patients experienced dysfunction of the end ileostomy. This was treated with conservative measures; however, it resulted in a prolonged hospital stay of 10 and 15 days, respectively. This complication was graded a grade 1 complication according to the Clavien scale. No infectious complications or reoperations were reported.

Postoperative pain scores and morphine requirement

The median pain score (VAS) was 4.5 on postoperative day 1 and decreased to score 3 on day 3. Correspondingly the morphine requirement decreased from $60 \mathrm{mg}$ on day 1 to $0 \mathrm{mg}$ on day 3 postoperatively.

Adhesions during completion proctectomy and pouch procedure

For five patients, a completion proctectomy with an ileoanal pouch procedure was performed through a transverse suprapubic incision at a median time after colectomy of 7 (IQR, 3.8-9.3) months. All patients showed absence of any adhesions in the pelvis, around the small bowel, or around the rectal stump. In two patients, adhesions of the cut side of the mesentery were present; these were scored as "limited adhesions present" by the surgeon.

\section{Discussion}

This study shows that the presented alternative extraction methods are technically feasible in patients who undergo laparoscopic emergency colectomy and are associated with a low morbidity rate and very limited adhesion formation at completion proctectomy in this small series.

Due to the transrectal specimen removal, the possibility of the development of intra-abdominal infections is present because of the prolonged time that the staple-line is opened to facilitate specimen extraction. However, neither postoperative abscesses nor increased adhesion formation at the rectal stump during subsequent completion proctectomy were observed. Nearly all patients were taking steroids or biologicals during surgery; however, we did not see any rectal stump related complications in patients who underwent transrectal specimen removal.
Although this study included only ten patients, it shows the feasibility of the extraction methods without preoperative complications. All patients in this series were in compromised clinical condition due to the colitis that failed to respond to medical therapy. For these patients especially, a minimally invasive approach is important to minimize surgical trauma and to prevent wound complications.

Many surgeons conduct laparoscopic-assisted colectomy or hand-assisted laparoscopic colectomy procedures (HALS) [20]. For colectomy specimen retrieval, mostly a periumbilical midline or transverse suprapubic (hand-port) incision is used. Wound infection rates from of $0-16 \%$ and minilaparotomy hernia percentages of $0-6 \%$ are reported $[20,21]$. Thus, this might delay a patient's recovery and influence cosmesis. Different laparoscopic procedures are developed to avoid the minilaparotomy and its associated complications, mainly wound infection [13-18].

There are some limitations to the laparoscopic procedures [22]. It can be difficult to extract a specimen from an obese patient with thickened mesentery or a specimen full of fecal content. It is therefore important to tailor the appropriate procedure to the individual patient. In this study, the patients were slim (median BMI, 21.5) and had no malignant disease. Close pericolic dissection was therefore justified facilitating specimen removal via the rectum or via the ileostomy site. Apart from close colon resection, preoperative bowel preparation is important to reduce the diameter of the bowel enabling easier extraction. In the acute setting, the bowel was generally empty or contained only fluid stools because of the colitis.

The single-port techniques require a larger incision than strictly necessary for the ileostomy, which increases the likelihood of future parastomal hernia. This technique must be reserved for patients who will have a later completion proctectomy and pouch procedure, where the stoma site is closed eventually. In patients with Crohn's disease and high likelihood of permanent ileostomy, the colon is best removed transanally. Because the presented extraction techniques are still considered experimental, it is important that laparoscopic subtotal colectomy and extraction of the specimen via one of the alternative routes is conducted in an audit setting.

This study suggests that the transrectal and transstomal extraction techniques are feasible and safe for retrieval of the colectomy specimen after laparoscopic subtotal colectomy with low postoperative morbidity and few intraabdominal adhesions. The foresights for these alternative extraction techniques are promising; however, the techniques still need refinement and are only applicable in selected patients.

Disclosures Drs. T.J. Gardenbroek, E.J. Eshuis, G.J.D. van Acker, P.J. Tanis, and W.A. Bemelman have no conflicts of interest or financial ties to disclose. 
Open Access This article is distributed under the terms of the Creative Commons Attribution Noncommercial License which permits any noncommercial use, distribution, and reproduction in any medium, provided the original author(s) and source are credited.

\section{References}

1. Hoie O, Wolters FL, Riis L, Bernklev T, Aamodt G, Clofent J, Tsianos E, Beltrami M, Odes S, Munkholm P, Vatn M, Stockbrugger RW, Moum B (2007) Low colectomy rates in ulcerative colitis in an unselected European cohort followed for 10 years. Gastroenterology 132(2):507-515

2. Bernell O, Lapidus A, Hellers G (2000) Risk factors for surgery and postoperative recurrence in Crohn's disease. Ann Surg 231(1):38-45

3. Louis E, Collard A, Oger AF, Degroote E, Aboul Nasr El Yafi FA, Belaiche J (2001) Behaviour of Crohn's disease according to the Vienna classification: changing pattern over the course of the disease. Gut 49(6):777-782

4. Cosnes J, Cattan S, Blain A, Beaugerie L, Carbonnel F, Parc R, Gendre JP (2002) Long-term evolution of disease behavior of Crohn's disease. Inflamm Bowel Dis 8(4):244-250

5. Keswani RN, Cohen RD (2005) Postoperative management of ulcerative colitis and Crohn's disease. Curr Gastroenterol Rep 7(6):492-499

6. Dunker MS, Bemelman WA, Slors JF, van Hogezand RA, Ringers J, Gouma DJ (2000) Laparoscopic-assisted vs open colectomy for severe acute colitis in patients with inflammatory bowel disease (IBD): a retrospective study in 42 patients. Surg Endosc 14(10):911-914

7. The Southern Surgeons Club (1991) A prospective analysis of 1518 laparoscopic cholecystectomies. N Engl J Med 324(16): 1073-1078

8. Bonjer HJ, Hop WC, Nelson H, Sargent DJ, Lacy AM, Castells A, Guillou PJ, Thorpe H, Brown J, Delgado S, Kuhrij E, Haglind E, Pahlman L (2007) Laparoscopically assisted vs open colectomy for colon cancer: a meta-analysis. Arch Surg 142(3):298303

9. Laurent C, Leblanc F, Wutrich P, Scheffler M, Rullier E (2009) Laparoscopic versus open surgery for rectal cancer: long-term oncologic results. Ann Surg 250(1):54-61
10. Muhe E (1992) Long-term follow-up after laparoscopic cholecystectomy. Endoscopy 24(9):754-758

11. Braga M, Vignali A, Zuliani W, Frasson M, Di SC, Di CV (2005) Laparoscopic versus open colorectal surgery: cost-benefit analysis in a single-center randomized trial. Ann Surg 242(6):890 895 (discussion)

12. Puente I, Sosa JL, Sleeman D, Desai U, Tranakas N, Hartmann R (1994) Laparoscopic assisted colorectal surgery. J Laparoendosc Surg 4(1):1-7

13. Gumbs AA, Fowler D, Milone L, Evanko JC, Ude AO, Stevens P, Bessler M (2009) Transvaginal natural orifice translumenal endoscopic surgery cholecystectomy: early evolution of the technique. Ann Surg 249(6):908-912

14. Rieger NA, Lam FF (2010) Single-incision laparoscopically assisted colectomy using standard laparoscopic instrumentation. Surg Endosc 24(4):888-890

15. Ostrowitz MB, Eschete D, Zemon H, DeNoto G (2009) Roboticassisted single-incision right colectomy: early experience. Int $\mathrm{J}$ Med Robot 5(4):465-470

16. Eshuis EJ, Voermans RP, Stokkers PC, van Berge Henegouwen MI, Fockens P, Bemelman WA (2010) Laparoscopic resection with transcolonic specimen extraction for ileocaecal Crohn's disease. Br J Surg 97(4):569-574

17. Romanelli JR, Earle DB (2009) Single-port laparoscopic surgery: an overview. Surg Endosc 23(7):1419-1427

18. Palanivelu C, Rangarajan M, Jategaonkar PA, Anand NV (2008) An innovative technique for colorectal specimen retrieval: a new era of "natural orifice specimen extraction" (N.O.S.E.). Dis Colon Rectum 51(7):1120-1124

19. Dindo D, Demartines N, Clavien PA (2004) Classification of surgical complications: a new proposal with evaluation in a cohort of 6336 patients and results of a survey. Ann Surg 240(2): 205-213

20. HALS Study Group (2000) Hand-assisted laparoscopic surgery vs standard laparoscopic surgery for colorectal disease: a prospective randomized trial. Surg Endosc 14(10):896-901

21. Hackert T, Uhl W, Buchler MW (2002) Specimen retrieval in laparoscopic colon surgery. Dig Surg 19(6):502-506

22. Tekkis PP, Senagore AJ, Delaney CP, Fazio VW (2005) Evaluation of the learning curve in laparoscopic colorectal surgery: comparison of right-sided and left-sided resections. Ann Surg 242(1):83-91 